\title{
ADORNO E A EDUCAÇÃO MUSICAL PELO RÁDIO*
}

\author{
IRAY CARONE*
}

RESUMO: Este artigo é uma exposição do estudo analítico de um programa semanal da National Broadcasting Company (NBC), The Music Appreciation Hour, destinado a crianças e jovens escolares, realizado por Theodor W. Adorno durante sua participação no Princeton Radio Research Project (1938-1941). Tem duas partes: na primeira, Adorno analisou a pedagogia musical do programa; na segunda, apontou para as implicaçōes culturais desse programa, que, embora não comercial e sustentado pela própria NBC, tinha todas as marcas da indústria do entretenimento comercial.

Palavras-chave: Theodor W. Adorno. Apreciação musical. Indústria do entretenimento. Projeto de Princeton.

\begin{abstract}
ADORNO AND THE MUSICAL EDUCATION THROUGH RADIO BROADCASTS
ABSTRACT: This paper is an exposition of the analytical study of The Music Appreciation Hour, a weekly classical music program of the National Broadcasting Company directed to children and young students, that Theodor W. Adorno carried out during his participation in the Princeton Radio Research Project (19381941). This study comprises two parts: in the first one, Adorno analyzed the musical pedagogy of the program, while in the second one, he pointed out the cultural implications of the program that, despite its non commercial character and NBC support, carried all the marks of the entertainment industry.
\end{abstract}

Key words: Theodor W. Adorno. Music appreciation. Entertainment industry. Princeton Project.

* À Márcia Carone, minha irmã.

** Professora Assistente Doutora aposentada do Instituto de Psicologia da Universidade de São Paulo (USP) e pesquisadora da Universidade Paulista (UNIP).E-mail: iraycarone@uol.com.br

Educ. Soc., Campinas, vol. 24, n. 83, p. 477-493, agosto 2003

Disponível em <http://www.cedes.unicamp.br> 
(egundo Horowitz (1993), antes da Primeira Grande Guerra, a pedagogia musical nos Estados Unidos da América do Norte enfatizava a necessidade de se aprender a ler música, a tocar um instrumento e a perceber a forma da sonata e outros elementos da estrutura musical. Daí surgiram os "apreciadores musicais", que se dirigiam às classes médias para popularizar um novo elitismo: o de tornar a "grande música" um privilégio democrático. Com o advento da radiodifusão, nos fins dos anos de 1920, os programas de música clássica concentravam-se na reputação e na personalidade - os grandes compositores, os grandes intérpretes - com estratégias publicitárias para vender catálogos de discos; a National Broadcasting Company (NBC), de David Sarnoff, comandava tanto a maior rede de estações de rádio da nação como a gravadora RCA Victor. A realização mais notável e prestigiada de Sarnoff foi a contratação de Walter Johannes Damrosch, concertista emigrado alemão, de 1928 a 1942, para um programa semanal de apreciação musical dirigido às crianças e aos jovens das escolas norte-americanas, como complementação ao currículo de música.

Quando Theodor W. Adorno foi contratado por Paul F. Lazarsfeld para participar da seção musical do Princeton Radio Research Project, em 1938, realizou um estudo analítico do já consagrado programa de educação de música clássica pelo rádio, The $N B C$ Music Appreciation Hour Conducted by Walter Damrosch. O artigo resultante desse estudo ficou nos arquivos da Universidade de Columbia (Nova York) até 1994, quando foi redescoberto por musicólogos e publicado, depois de 55 anos, na revista The Musical Quarterly.

É interessante notar que o artigo de Adorno, intitulado "The analytical study of the NBC Music Appreciation Hour”, não foi publicado pelas duas antologias do Radio Research, por razóes que agora se tornaram bastante óbvias: ele não agradou a ninguém. Muito embora Adorno já fosse reconhecido como um excelente conhecedor de música clássica (a despeito das discordâncias de Bernard $\mathrm{H}$. Haggin, em Music in the nation) a sua crítica musical tornou-se inaceitável na época, porque atacava um programa educativo, aparentemente sem fins comerciais e não lucrativo, promovido pela rede para pessoas em idade escolar, de várias partes do país, que não podiam ter o privilégio de freqüentar as grandes salas de concertos.

Esse programa atingiu no ano de 1937 , segundo consta, cerca de 7 milhôes de estudantes de 70 mil escolas dos Estados Unidos. 
Dirigido por Damrosch, cujos arranjos musicais eram executados pela orquestra da NBC, a sua programação era semelhante, mas bastante ampliada, ao repertório gravado por Toscanini na RCA Victor.

A rigor, o programa objetivava popularizar a música clássica e ao mesmo tempo fazer de Damrosch (que Adorno e os europeus não tinham em alta conta como músico) "o principal embaixador americano da compreensão e da apreciação musicais" (Horowitz, 1993) para as crianças e os jovens das escolas norte-americanas. Obviamente, era dedicado ao ensino complementar da "apreciação da música" por intermédio do meio de comunicação mais abrangente, popular e ubíquo de que se tinha notícia: o rádio. Era acompanhado por quatro manuais dirigidos aos estudantes (Student's Worksheets) e um guia dos professores de música (Teacher's Guide), publicados pela editora da Universidade de Columbia em 1939.

$\mathrm{O}$ objetivo de Adorno, segundo as suas próprias palavras, era o de mostrar que a radiodifusão, mesmo quando se propóe a colocar no ar programas musicais de caráter puramente educacional, falhava em levar os ouvintes-destinatários a uma relação viva e real com a música, ou seja, a ter uma verdadeira "experiência musical".

Além de acompanhar as apresentações musicais do programa, que ocorriam às sextas e aos sábados, Adorno tomou como objeto de análise os materiais impressos para os professores e alunos "virtuais" (ao que tudo indica, o programa foi muito bem-sucedido nas escolas, pois Damrosch chegava a receber cerca de 50 mil cartas de alunos por ano).

Essa análise disse respeito à pedagogia musical do programa e às suas implicações culturais. Na primeira parte, foram examinados criticamente os postulados implícitos nos quatro manuais do estudante. $\mathrm{Na}$ segunda parte, o alvo principal da crítica adorniana foi a "estética do efeito", que reduzia a apreciação musical ao prazer ou à diversão derivados da audição, subordinando a música séria às exigências da indústria do entretenimento comercial, condicionando o ouvinte a um tipo de audição regredida e convertendo a cultura musical numa cultura de aparência.

Embora a expressão "indústria cultural" tenha aparecido posteriormente, na Dialética do esclarecimento, os modelos de crítica cultural de Adorno já se estavam esboçando nesse estudo analítico: músicas clássicas, geradas muito antes da sociedade industrial e gozando de autonomia como obras de arte, foram convertidas em 
pseudocultura pelos monopólios comerciais da música, com a finalidade de "democratizar" a música clássica e promover uma aparente "elevação cultural" das audiências:

Será mostrado que não apenas há insuficiência na parte puramente musical e pedagógica do programa, mas também que ele conduz a um mundo musical fictício dominado pelos nomes de personalidades, etiquetas estilísticas e valores pré-digeridos que não podem ser "experienciados" pela audiência do Music Appreciation Hour; na verdade, o programa apresenta o material de modo a fomentar, de modo proposital ou não, atitudes estereotipadas e convencionais, ao invés de levar à compreensão concreta do sentido musical. (Adorno, 1994, p. 326)

Embora reconhecendo a existência de algumas idéias excelentes nos materiais impressos, bem como os esforços da rede NBC para a preparação e organização dos concertos, Adorno disse que as falhas da pedagogia musical do programa foram devidas a causas mais profundas:

Consideramos como a mais importante dessas causas a tendência ideológica mencionada no artigo sobre uma crítica social da música no rádio. $\mathrm{O}$ rádio, como uma empresa dentro de uma cultura comercial, é forçado a promover, no interior do ouvinte, uma atitude ingenuamente entusiasta com relação a qualquer material que se lhe ofereça, e assim, indiretamente, em relação ao próprio rádio. Este viés "promocional" do rádio é um obstáculo permanente para se alcançar uma relação adequada com um material musical preeminentemente sério. (Idem, ibid., p. 327)

\section{Análise pedagógica e musical}

A primeira parte, como já dissemos, é a análise pedagógica e musical do conteúdo dos quatro cursos dos manuais do estudante. $\mathrm{O}$ objetivo mais geral destes era o de conduzir os estudantes do "lado de fora" para o "lado de dentro" da música, por meio dos seguintes passos: (1) Série $A$ - estudo da família orquestral, ou seja, dos instrumentos musicais; (2) Série $B$ - estudo das idéias e imagens transportadas pelo veículo musical; (3) Série $C$ - estudo da estrutura e das formas da música pura; e (4) Série $D$ - estudo do significado da música como expressão da vida e da época do compositor. Pretendiam levar o estudante a entender o mundo musical por etapas e de acordo com o desenvolvimento psicológico das crianças: dos aspectos físicos e imaginativos da música aos mais abstratos e intelectuais, ou seja, à teoria musical propriamente dita. De acordo com o guia do professor: 
Não levando em consideração a ordem seguida, entretanto, o atrativo da Série $A$ depende em larga medida do grau de familiaridade que as crianças possam vir a ter dos vários instrumentos orquestrais como personalidades e não meros sons desencarnados. Daí a importância de se usar cartóes coloridos de instrumentos ou de trazer alguns instrumentos reais para as salas de aula sempre que for possível. (Idem, ibid., p. 330)

Adorno disse, a esse respeito, que não se devia exagerar a importância do lado descritivo e físico da música, porque, embora haja uma tradição que "personaliza" os instrumentos orquestrais, os sons instrumentais são apenas meras funções da estrutura do todo da música, sem nenhum valor intrínseco como sons individuais. Neste sentido, a atenção do estudante não devia ser desviada pedagogicamente para o que é apenas subsidiário, ou seja, os meios não deveriam substituir os fins. Orientada para discernir os sons de uma flauta ao ouvir uma sinfonia de Haydn, por exemplo, a criança poderá se sentir "traída" pelos adultos, pois "numa sinfonia de Haydn os instrumentos não falam como personalidades, mas funcionam dentro da coerência das partes" (idem, ibid.). Além disso, uma criança que espera pela entrada deste ou daquele instrumento, ao ouvir uma sinfonia, pode não ouvir a própria música ao se concentrar no reconhecimento de cada instrumento. A sua mente habitua-se a se concentrar em aspectos técnicos (technique-minded), com a conversão dos meios (instrumentos) em fins em si mesmos, numa atitude fetichista com relação à música.

Com relação aos aspectos imaginativos, objeto da Série $B$, Adorno disse que raramente aparecem "descrições da natureza" ou algo semelhante na música. Não obstante isso, o manual do estudante dizia, a respeito de "animais na música":

A "Cavalgada das Valquírias" descreve o vôo dos cavalos através das nuvens. Nós ouvimos os sons dos cascos no galope (trompa e violoncelo), os seus relinchos (instrumentos de sopro), a canção de batalha das virgens (trombetas e trombones) e os seus sinistros gritos de guerra (instrumentos de corda). (Idem, ibid., p. 333)

No entanto, as Valquírias e os cavalos são apenas entidades míticas pelas quais a música de Wagner tenta transfigurar as nuvens, a tempestade e o relâmpago. A "Cavalgada das Valquírias" é o que se pode chamar de mitologização musical de uma trovoada e nada mais que isso. Logo, dificilmente a criança irá perceber cavalos relinchando ou galopando, ao ouvir o que não pretende ser uma 
descrição física da natureza. Seria suficiente, diz Adorno, contar a ela algo sobre o mito das Valquírias e o ritmo da música.

Outro problema apontado por Adorno, na Série B, disse respeito aos temas musicais. Pretendia-se criar o hábito nos estudantes de se dar a atenção aos temas, a tocá-los ou a segui-los, como uma abordagem mais externa do que interna à música:

O tema sendo o "lado de fora" da música e a estrutura "o lado de dentro", a tendência em direção à audição atomística (que é o problema principal da crítica social da música no rádio) é aqui expressamente fomentada pelo Music Appreciation Hour. A idéia de que o tema é "o mais fácil” na música conduz novamente a uma mudança da atenção do todo para a parte. (Idem, ibid., p. 331)

A audição atomística é, na verdade, uma forma de regressão da audição, que torna impossível a compreensão de uma sinfonia como uma unidade completa e funcional, na qual o tema e o seu desenvolvimento não podem ser separados. A criança, entretanto, pode ser conduzida a uma apreensão da totalidade ou da unidade musical através de um método simples, sugerido por Adorno: ela deve tocar ou cantar uma melodia infantil tal como London bridges is falling down. Em seguida, como aprendeu a canção sem lhe ocorrer que ela tem um "tema" distinto do desenvolvimento, poderá analisá-la segundo o motivo fundamental que é repetido e variado. Dessa forma, poderá entender que o tema nada mais é que um material do movimento e não o seu objetivo ou essência. A noção de tema, então, não desaparecerá, mas a ele será dado o seu lugar certo e ganhará por aí o seu verdadeiro significado. A necessidade fomentada pelos educadores musicais de levar os alunos a "reconhecerem" uma música pela identificação ou citação de seus temas repousa numa concepção fetichizada da música, cujas implicações culturais Adorno pretendeu tirar na segunda parte de sua análise.

A Série $D$ apresentava um programa de Bach precedido por um resumo de sua biografia, corretamente caracterizando-o como o fim de uma era e o começo de outra, pois foi o último grande compositor da escola polifônica e, ao mesmo tempo, o fundador de toda a música moderna. No entanto, dentro da abordagem que pretendia ir do concreto para o abstrato, o manual dizia: "Bach nasceu na pequena cidade de Eisenach, Alemanha, à sombra do castelo Wartburg, que é também conhecido por nós como o local de uma das grandes cenas do Tannhäuser de Wagner” (Adorno, 1994, p. 334). 
O elo estabelecido entre Bach-Eisenach-Wartburg-TannhäuserWagner, diz Adorno, é puramente fortuito, não tendo nenhuma base na música e nos compositores em questão: o castelo Wartburg tem certas associaçôes com cavalheiros, glamour medieval, armaduras brilhantes e lindas donzelas; na música de Bach não há absolutamente nada que sugira tais características. Conseqüentemente, é de uma absoluta falta de gosto introduzir Bach em termos de um herói operístico, ou não distinguir o compositor de suas criaturas, contribuindo para colocá-los no mesmo panteão de grandeza, indiscriminadamente adorados pelo lado externo.

Apesar de as críticas de Adorno à pedagogia adotada pelo programa terem sido, até agora, muito pontuais, as suas análises da teoria musical, explícita ou implícita a ele, foram as mais sérias e definitivas. Sem dúvida, a parte conceptual dos manuais era a que mais comprometia negativamente o objetivo educacional do programa da NBC.

A introdução da teoria musical dos manuais correu por conta de Charles H. Farnsworth e outros especialistas, mas os conceitos principais foram expressos de tal modo que se tornaram incompreensíveis para aqueles que não tinham familiaridade com as estruturas musicais. Ao tentar descrever a música como unidade estrutural, o autor usava a expressão "movimento ideal" para caracterizar uma melodia, tentando passar a idéia de que os movimentos musicais não são movimentos que ocorrem no mundo externo, mas dentro da esfera particular do som estruturado. O termo "ideal", por sua vez, carregava consigo associaçōes erradas, a do padrão da perfeição platônica. Segundo Adorno, essa asserção incompreensível para crianças e jovens seria fundamental para o entendimento da estrutura e das formas musicais, objetivo maior da Série $C$.

Adorno sugeriu, dentro da abordagem externo/interno da pedagogia do programa, que a relação entre a abertura e a sinfonia fosse explicada imediatamente quando o "Coriolanus" estivesse sendo apresentado pela orquestra, ou seja, como o momento correto para se entender a abertura como um enredo dramático. Dessa maneira, as sinfonias posteriormente executadas seriam apreendidas pelos alunos como indissociadas da abertura, ou seja, como dramas musicais.

A apresentação da sequiência das formas musicais, no programa, pareceu se basear na suposição de que o desenvolvimento histórico da música coincidia com o desenvolvimento do simples ao complexo, o 
que é palpavelmente absurdo, diz Adorno. A velha forma da fuga, por exemplo, é uma das mais difíceis de ser entendida pelo leigo. O procedimento pedagógico correto seria discutir a forma da fuga em contraste com a sua contrapartida, a forma da sonata; depois de elaborar as semelhanças e os contrastes entre as duas mais "integrais" formas musicais, poder-se-ia esclarecer que a primeira é fundamentalmente estática e a segunda, dinâmica, bastando para isso comparar uma fuga de Bach, ou de algum predecessor, com uma sonata de Beethoven.

Outra impropriedade pedagógica dos manuais, segundo Adorno, era a sua abordagem dos compositores, como se houvesse um desenvolvimento unilateral e evolutivo da música: primeiro, apresentavam um concerto de Bach; depois, um concerto de Händel, até se chegar às sinfonias românticas de Tchaikovski. As últimas, no entanto, estariam mais próximas da consciência musical dos jovens, acostumados com a música romântica de efeitos emocionais.

Adorno sugeriu, então, uma seqüência diferente e inversa à primeira: primeiro, apresentação e discussão de peças sinfônicas de Schubert, não só por causa da pequena dificuldade em segui-las, mas também para que o aluno aprendesse a analisar o seu esqueleto estrutural. A seguir, se tornaria mais fácil abordar Haydn, harmonicamente mais primitivo que Schubert, mas com maior densidade temática que aquela que encontramos no primeiro movimento da Sinfonia em C maior de Schubert. Desse modo, o aluno poderia reconhecer neste as formas que já aprendeu naquele. A discussão sobre Haydn poderia ser conduzida suavemente para Mozart, de tal modo que as diferenças entre os seus métodos de composição pudessem ser mostradas e compreendidas. A partir dos três concertos anteriores, estaria preparado o caminho para se entrar numa sinfonia de Beethoven. Os artifícios polifônicos do período tardio da obra de Beethoven, por sua vez, constituiriam uma boa transição para uma discussão da música de Bach, que deveria ser iniciada com peças nãocontrapontísticas.

De qualquer maneira, os concertos não deveriam ser apresentados mediante "arranjos" orquestrais, tal como Damrosch vinha fazendo, mas "em sua clareza original e economia de meios" (idem, ibid., p. 339).

A seguir, Adorno analisou todos os erros pedagógicos e conceituais do programa, sobretudo da Série C: a falta de especifici- 
dade na explicação na forma do rondó e o "efeito devastador" dessa falha explicativa, quando se tem de tratar do mais importante tipo de forma musical, a sonata (essencialmente diferente da primeira):

Compreender a sonata significa ouvir do modo correto, nada mais e nada menos. Como o Music Appreciation Hour ajuda a fomentar tal escuta? A forma da sonata é explicada pelo Hour em termos absolutamente esquemáticos, tais como: exposição, desenvolvimento e recapitulação. Podemos esperar, então, que o jovem ao ouvir, pela primeira vez, que a sonata é intelectualmente sofisticada e que a sua forma é A-B-A, julgará a música como muito barulho por nada. (Idem, ibid., p. 343)

Erroneamente, pois, o princípio do "desenvolvimento" que governa o todo da forma da sonata é reduzido, nessa explicação, à seção do meio oficialmente chamada de desenvolvimento. Três pontos deveriam ser absolutamente esclarecidos para o aluno alcançar uma compreensão real da forma da sonata, sem a qual Haydn, Mozart e Beethoven "permanecerão livros fechados para ele": (a) o princípio do desenvolvimento geral, ou princípio dinâmico, como base da forma da sonata; (b) o fechamento e a economia completa da forma da sonata (em comum com a fuga, embora ela seja fundamentalmente dinâmica); (c) a sonata como a tentativa de se alcançar uma unidade musicalmente completa dentro da multiplicidade.

\section{A promoção da pseudocultura musical}

Disse Adorno que as falhas pedagógicas e musicais do programa da NBC, evidenciadas pela análise, combinavam com uma idéia antiintelectualista da própria apreciação musical, ao reduzi-la aos efeitos da música sobre o ouvinte:

A apreciação seria a soma total dos efeitos musicais no ouvinte. É uma noção comum em estética desde a definição de tragédia por Aristóteles como uma forma de arte cujo objetivo era o de produzir os efeitos de piedade e medo no espectador. Goethe estava plenamente consciente do perigo disso quando escreveu: "a perfeição da obra de arte em si mesma é o postulado eterno e indispensável. Que pena que Aristóteles, que sempre teve o perfeito diante de si, tivesse pensado no efeito!". (Idem, ibid., p. 353)

É fácil perceber que a estética do efeito é mais perigosa ainda quando se vive numa sociedade de mercado, que vive de provocar efeitos comportamentais no consumidor. Além disso, é uma com- 
preensão incorreta da "apreciação" supor que o efeito da obra de arte seja idêntico ao seu significado, ou que a intenção da obra de arte é a de criar tal efeito.

No caso de uma experiência estética inteiramente adequada, o efeito da obra de arte e a apreensão plena do seu significado, por um ouvinte ideal, coincidirão. Mas esta coincidência não se presume existir quando se trata da apreciação musical das crianças e dos jovens. Dessa maneira, diz Adorno, é um erro do programa supor ou tratar os seus alunos como "ouvintes ideais" para os quais o significado da obra de arte e o efeito sobre eles coincidirão. Na verdade, o efeito da música seria concebido, pelo programa, como o ponto de partida da apreciação, mas também o seu ponto de chegada ou objetivo - o que é um evidente círculo vicioso. Talvez isso sinalizasse, afinal, a pouca relevância dada pelo programa à compreensão intelectual da música, como se a apreciação fosse uma mera fruição sensorial da arte musical, um encantamento dos sentidos. Mas, o que seria o "efeito", de acordo com o guia do professor?

A discussão pode incluir (...) se a peça "permanece coerente" quase até ao ponto da monotonia, ou se ela muda continuamente até aonde a imaginação levar, a nenhum lugar em particular, ou se ela tem a medida suficiente do "mesmo" e do "diferente" (unidade e variedade) para nos agradar. (Apud Adorno, 1994, p. 354)

Para um jovem sem experiência musical, diz Adorno, uma peça de música moderna avançada parecerá levar "a nenhum lugar em particular”, justamente porque ele é incapaz de compreender as relações sutis que constituem a sua estrutura ou o padrão complicado de sua forma. Mas, então, o compositor deveria ser proibido de escrever tal obra?

Isso significaria a inauguração da lei do mínimo esforço como a qualidade suprema da música, e a auto-satisfação filistina e a ignorância seriam os juízes de seu valor estético. Isso sem dizer que não apenas a compreensão, mas também o prazer, no sentido primitivo recomendado pelo Hour, varia de sujeito para sujeito, e que algo que "nos agrada" tal como é concebido pelo Hour pode vir a impedir uma consciência musical mais altamente desenvolvida, $\mathrm{e}$ vice-versa (Adorno, 1994, p. 355).

Este é, sem dúvida, o ponto principal da crítica de Adorno ao programa de educação musical pelo rádio: se o efeito é o propósito da música séria, então a "boa música" é aquela que satisfaz o ouvinte 
e nada exige dele. E como o ouvinte sempre tem razão, como eventual comprador de discos, o que será da música séria que não atinge o seu senso musical já administrado comercialmente e reafirmado pelo programa?

Por meio do discurso do "nós" que deveríamos ser agradados, existe a idéia insustentável de um "sentimento musical natural". Esse "sentimento musical natural" não existe: é apenas a aparência de atitudes historicamente mutáveis, e pode-se dizer seguramente que o que é hoje chamado de "natural” musicalmente é sobretudo o resíduo de convenção passada. (Idem, ibid.)

Assim, algo que é resíduo social de convenções passadas é representado como um traço inerente do próprio material musical; o uso "moderado" da dissonância, por exemplo, é recomendado pelo programa, como se ela não fosse muito "natural" aos nossos ouvidos.

A apreciação musical é, no fundo, convertida em prazer e diversão. Não há dúvida alguma de que a noção de "diversão" (fun), popular nos Estados Unidos e, numa certa medida, na Inglaterra, acaba jogando aqui um papel estético. Relacionada com humor, diversão e relaxamento, essa noção pressupõe que a arte não deva ser "séria”, nem mesmo na esfera estética, postulando, ao contrário, que a arte é contra a realidade árdua da vida real:

A noção de "fun" reflete um processo social que mecaniza e oprime o indivíduo num tal grau que no seu tempo livre ele deve sentir alívio de suas responsabilidades. Em nossa época, esse alívio assume, sob o nome de "fun", a forma de uma regressão à infância. O adulto que declara ter "fun" está moldado pelo padrão do menino brincalhão, descuidado, frívolo, que certamente não existe como ouvinte musical. (Idem, ibid., p. 374, nota 18)

Em outras palavras, ao conectar a apreciação musical com o prazer e a diversão, no sentido regredido da diversão, os educadores estão subordinando a música às categorias dos bens de consumo, particularmente com o entretenimento comercial e a estética prática advogada pelo programa.

Segundo o manual do aluno, aqueles que usam suas mentes mais ativamente obterão mais prazer ou diversão na escuta musical dos concertos. Mas, diz Adorno, quanto maior a atividade mental, menor o relaxamento do sujeito que ouve e, portanto, maior será a distância com a diversão. A música séria, ouvida de modo ativo ou passivo, não promove a diversão por sua própria natureza. 
Mesmo substituindo o termo "diversão", tão próprio da indústria do entretenimento, pelo termo "prazer" (pleasure), diz Adorno, ainda assim estaríamos usando "qualitativos gustativos" para a música, ou seja, advogando um hedonismo musical (reivindicado explicitamente nos livros de Carl Seashore e Deems Taylor) que nos traz, por associação, a imagem de um violinista cigano tocando uma peça de Beethoven num café-concerto. A beleza dos coloridos musicais seria então comparável à sensação de beleza experimentada diante de pinturas ornamentais de um pôr-do-sol ou de uma bela jovem, ou seja, de uma beleza "natural" que não transmite jamais a idéia de algo que é "estruturalmente belo".

Assim, de acordo com os manuais da Série $C$, numa sinfonia, o primeiro movimento exige que prestemos atenção aos seus padrões complicados; o segundo permite-nos sonhar; o terceiro, relaxar; e o quarto eleva o nosso espírito a um alegre estado de exaltação mental. Isso lembra, diz Adorno, a receita de felicidade dada aos pobres: se eles dormem num quarto frio, precisam apenas de colocar o pé para fora do cobertor para sentir maior prazer e conforto em recolocá-lo sob o seu calor. O segundo e o terceiro movimentos de uma sinfonia, descritos inadequadamente como momentos que nos permitem sonhar e relaxar, não correspondem à maior parte das sinfonias (como o segundo da Quarta Sinfonia de Brahms, que não é menos complicado que o primeiro). O mesmo acontece com o movimento final da sinfonia, que não conduz a um "eufórico estado de exaltação mental", pois podemos ouvir uma peça musical altamente excitante de forma atenta e compreendê-la sem nos excitarmos.

Embora o programa tentasse tornar a música séria acessível às crianças, substituindo a expressão "grande obra de arte" pelos termos "diversão" e "prazer", o resultado final foi o barateamento da música sem, no entanto, diminuir a necessidade de adoração dos músicos como líderes espirituais. A educação musical, diz Adorno, não significa a adoração dos músicos, mas sim o respeito pela obra, manifestado pela preocupação do ouvinte com o sentido musical per se.

O prazer da apreciação musical, segundo os métodos do programa, coincidiria com o prazer do reconhecimento: "A música que é conhecida e relembrada até que possa ser assobiada ou cantada ou ser revista silenciosamente na mente, torna-se amada e é ouvida com apreciação" (apud Adorno, 1994, p. 358). Ora, diz Adorno, não há dúvida de que o reconhecimento tem um papel importante na experiência musical. Mas o programa estava enfatizando, de fato, 
um prazer não-espontâneo e não-imediato: o de possuir um conhecimento musical como uma propriedade. Mas isso está longe, sem dúvida, da verdadeira compreensão musical. É o prazer do avarento que aprecia o ouro que acumulou.

$\mathrm{O}$ culto das personalidades, que não é novidade na história da música, foi também uma característica marcante do programa. A função do culto da personalidade na música teve, no entanto, um aspecto progressista no século XVI e no começo do XVII. Mas, atualmente, diz Adorno, desempenha um papel manipulador no setor musical. No caso do programa, o regente Damrosch foi coroado por um halo de poderes misteriosos e mágicos de personalidade: "Mr. Damrosch volta-se para a orquestra, ondula no ar a sua batuta como uma varinha mágica e instantaneamente lindas músicas são ouvidas em centenas de salas de aulas, do Maine à Califórnia. Nenhum conto de fadas é mais maravilhoso que isso" (idem, ibid., p. 361).

Os compositores, tais como Beethoven e Mozart, são transformados em "gênios musicais", ou seja, em gigantes, em flagrante analogia com os contos de fadas, de onde emergem miraculosamente. No entanto, nenhuma explicação é dada porque são considerados superiores com relação a outros compositores.

Seria uma boa idéia abrir um programa nesse curso, falando aos alunos: "Vocês ouviram que Beethoven é um grande compositor e essa conversa provavelmente os irrita. No mínimo, gostariam de saber por que ele é grande quando comparado a outros compositores. É porque colocou um coro final na Nona Sinfonia, ou porque a ópera Fidélio é baseada em idéias humanitárias? É porque introduziu a expressão subjetiva como um elemento básico da música? Esta última é certamente a sua contribuição mais notável, mas se desejarmos compreender a música de Beethoven, devemos saber como a expressão subjetiva pode ser percebida dentro da obra de Beethoven e como, nos seus elementos específicos, essa música é superior a outra música”. Então, poderemos comparar a música de Beethoven com a de seus contemporâneos. Apontaremos para os elementos específicos de sua técnica, tal como a economia estrita de suas composições que utiliza cada pedaço do material temático e não apresenta nada que não tenha uma função dentro do todo. (Idem, ibid., p. 362)

Poderiam ser acrescentadas, para se dar pleno sentido musical ao termo "grandeza", as comparações entre compositores cujo principal valor foi o de representarem adequadamente o seu tempo (Corelli, Lully e, numa grande medida, Händel) e Beethoven, cuja música é inerentemente um ataque às convençōes musicais de seu 
tempo. As explicações poderiam ajudar na compreensão da música séria moderna, que assim poderia ser interpretada como uma herança de Beethoven. Quando os alunos tiverem aprendido isso, não terão necessidade de chamá-lo de "gigante" e perceberão a sua singularidade na devida proporção, não apenas historicamente, mas também em termos absolutos.

Mas o máximo dessa exaltação de gênios da música foi dirigida ao próprio Damrosch, numa linha de alta pressão publicitária da NBC. Embora Damrosch não estivesse consciente disso, a publicidade jogava conjuntamente os holofotes sobre a NBC, nos manuais dos alunos:

Então apareceu o rádio. Mr. Damrosch viu que através dessa maravilhosa invenção ele poderia tocar praticamente a todos os jovens da nação. Com a ajuda da National Broadcasting Company, ele fundou The NBC Music Appreciation Hour, e por onze anos tem conduzido estes programas das sextas-feiras (...). Percebendo que através desse maravilhoso e novo meio ele poderia atingir milhões de ouvintes, ao passo que antes apenas tocava para algumas centenas de pessoas, organizou, com a cooperação da National Brodcasting Company, a série de programas de concertos conhecida como The Music Appreciation Hour. (Apud Adorno, 1994, p. 364)

Damrosch não era, de fato, um músico de valor notável (o que não prejudicaria o empreendimento pedagógico do programa), mas as fotografias e os letreiros que as acompanhavam, "O seu condutor, Walter Damrosch", sugeriam que esse esplêndido e velho homem, "esse Wotan da música clássica descia das suas alturas e dava toda a sua energia amorosa para as pequenas crianças".

A idéia de "sucesso", emprestada da competição comercial, foi também usada para designar o padrão musical dos compositores. $\mathrm{Na}$ introdução ao programa de Beethoven, da Série $D$, foi dito:

O gênio de Beethoven não teve de esperar pelo reconhecimento póstumo. Ele rapidamente alcançou a fama e se tornou bem-sucedido. Muito antes de sua morte, teve a satisfação de saber que era considerado o maior compositor de seu tempo. (Apud Adorno, 1994, p. 365)

A aprovação pública e a remuneração tornaram-se, pois, os critérios para se julgar o alto padrão musical de Beethoven. No caso em questão, é bem sabido que Beethoven nunca se tornou bemsucedido comercialmente, embora não tenha passado fome. $\mathrm{Na}$ verdade, quando alguns dos aristocratas austríacos, que lhe garantiam uma pequena pensão, morreram, parte dela foi cancelada e Beethoven 
precisou entrar em litígio para obter esse dinheiro. Mais tarde, caiu em dificuldades financeiras por causa de seu sobrinho e, aproximadamente, em 1821, foi preso pela polícia por causa de sua aparência miserável. No caso de Wagner, o programa usou o mesmo padrão de avaliação: a história de um homem que lutou na juventude e foi devidamente remunerado na maturidade, segundo o ditado latino per aspera ad astra.

Novamente, diz Adorno, ocorreu uma distorção histórica da realidade, em prol da reafirmação da ideologia da cultura que entroniza os bens materiais e o sucesso nas finanças. Ora, isso significa também desvalorizar a música séria que ainda não alcançou aprovação pública e fomentar uma atitude reacionária em termos musicais. Cita alguns exemplos do programa: a música do "excêntrico" Mahler é preterida pelo "gênio" Sibelius, e a música de Samuel Barber é valorizada pela sua "moderação no uso da dissonância".

A totalidade dessas características do programa, Adorno chamou-a de tendência para produzir "Babbitts" musicais (referência ao personagem George Babbitt, de Sinclair Lewis, que simboliza a mediocridade cultural do homem norte-americano). A "babiteria" (babbittry) musical, com sua ênfase no efeito da música sobre o ouvinte, fomenta a idéia de que o relaxamento prazeroso é a própria função da música. Neste sentido, é fácil imaginar que a música é o descanso do guerreiro, isto é, do homem de negócios que após a labuta se permite uma espécie de entrega ao sentimentalismo musical. $\mathrm{O}$ antiintelectualismo manifesto por essa atitude também se revela na astúcia com relação aos valores que mandam no mercado: para a "babiteria", a importância de alguma coisa pode ser medida e expressa em termos quantitativos, ou seja, em termos do dinheiro que foi gasto com ela.

A conclusão de Adorno, ao final da análise, é de que se a mentalidade filistina grassa entre aqueles que receberam educação musical, então não se poderá esperar que os jovens, musicalmente não-conscientes, tornem-se melhores que os seus educadores.

\section{Conclusões}

A iniciativa educacional da NBC poderia merecer elogios por ser um serviço público prestado pelo rádio, em prol da democratização da cultura musical. No entanto, a análise de Adorno permitiu 
mostrar como ela obedeceu aos interesses dos monopólios comerciais no setor musical, pela via da transmissão radiofônica. Não aparecia como "business" porque não contava com patrocínio comercial e implicava enormes despesas da NBC. Mas tinha todas as marcas da indústria do entretenimento, de modo que a intenção educativa foi solapada por uma intenção comercial não confessada: a de vender a música clássica, além de vender uma imagem promocional da rede NBC. Parece que a regra de ouro para se comercializar os clássicos é a de converter a cultura em pseudocultura musical, a formação do ouvinte em semiformação e a apreciação musical em diversão.

A análise hipercrítica de Adorno poderia até parecer injusta e impertinente diante do enorme esforço da NBC. Mas parece que hoje, quando a indústria cultural da música já realizou os seus objetivos e chegou, com isso, à sua plena e horrenda visibilidade, as suas palavras não parecem ser tão indigestas quanto nos anos de 1930 e 1940. Essa é, inclusive, a opinião de muitos críticos musicais dos anos de 1990 para cá, como se Adorno tivesse diagnosticado a doença ainda quando os sintomas eram iniciais e confusos, fora de um enquadre definido.

Em última análise, a "apreciação musical” conduzida pelo programa, sob a pressão dos monopólios comerciais do setor musical, criou uma espécie de homogeneidade (ou nivelamento por baixo) entre a música como arte autônoma e a música popular comercial, por meio do poder de massificação do rádio como um grande executor das tendências objetivas de deterioração cultural e da regressão da audição.

O programa de apreciação musical pelo rádio foi um fenômeno tipicamente norte-americano, que dependeu da existência de grandes corporações capitalistas invadindo o setor musical, de um lado, e de grandes redes de emissoras de rádio a percorrer o país inteiro, de outro. Mas hoje os monopólios da música usam uma grande diversidade de estratégias para vender seus produtos, em qualquer parte do mundo. De certa maneira, os programas de apreciação musical parecem ser uma coisa ultrapassada, como estratégias para atrair consumidores. Os discos compactos de música clássica, os mais vendáveis, atomizam e trituram a música clássica de modo tal que podemos ouvir uma série de trechos musicais, extraídos de vários compositores de épocas diferentes, numa tacada só, sem maiores esforços de compreensão e apreciação 
musicais. Essa tendência objetiva equivale a impor, no plano subjetivo, um único padrão de escuta da música, popular ou séria: atomístico, desconcentrado, pouco exigente etc. Adorno tinha razão quando não parecia ter razão, ao apontar para os elementos ocultos de uma programação de música clássica dos anos de 1930, que se desnudaram no curso do tempo. Afinal de contas, tudo é diversão do ouvinte e lucro das gravadoras. Isso é cultura?

Recebido e aprovado em maio de 2003.

Referências bibliográficas

ADORNO, T.W.; HORKHEIMER, M. Dialética do esclarecimento: fragmentos filosóficos. Rio de Janeiro: Zahar, 1985.

ADORNO, T.W. Analytical study of the NBC music appreciation hour. The Musical Quarterly, Oxford, v. 78, n. 2, p. 326-377, 1994.

HAGGIN, B.H. Music in the nation. New York: Duell, Sloan and Pearce, 1949.

HOROWITZ, J. Professor Leny. New York Review of Books, Nova York, v. 40, n. 11, p.1-2, 10 jun. 1993. 